\title{
Silica Supported MTSA Catalyst for the Synthesis of 5-Substituted-1H-tetrazole- A Green Chemistry Approach
}

\author{
DHARMESH H. MAHAJAN*, DIPESH MISTRY and HETAL TAILOR
}

Government Science College, Fort-Songadh, Dist-Tapi, Gujarat, India

mahajandh@gmail.com

Received 9 April 2018 / Accepted 1 May 2018

\begin{abstract}
We have developed simple, cost efficient and environmentally benign protocol for the synthesis of 5-substituted $1 \mathrm{H}$-tetrazole via [2+3] cyclo addition reaction from organic nitrile and sodium azide in refluxing DMF by using heterogeneous catalyst as MTSA (Melamine tri sulphonic acid). The corresponding 5-substituted $1 \mathrm{H}$-tetrazole were obtained in lower yield but when using silica supported MTSA the yield obtained $85 \%$ in $6 \mathrm{~h}$. After completion of the reaction, the catalyst was recovered by filtration and reused with only a slight decrease of activity observed under the same reaction conditions. Various aliphatic and aromatic nitrile converted in corresponding 5 -substituted $1 \mathrm{H}$-tetrazole in excellent yield without any contamination.
\end{abstract}

Keywords: 5-Substituted-1H-tetrazole, Aryl nitriles, Sodium azide, MTSA, Silica, Supported, Catalysis

\section{Introduction}

Tetrazoles which represent a significant class of heterocycles have attracted considerable interest in recent years because of their wide utility. Tetrazoles are heterocyclic compounds having a five membered ring containing one carbon and four nitrogen atoms. Tetrazoles are used in coordination chemistry as ligands, in medicinal chemistry as stable surrogates for carboxylic acids and in materials applications, including explosives, rocket propellants and agriculture $^{1-9}$. An advantage of tetrazolic acids over carboxylic acids is that they are resistant to many biological metabolic degradation pathways ${ }^{3}$. The preparations of substituted tetrazoles have been the subject of intense investigation especially from the nitrile functionality, which is widely recognized as a useful intermediate in organic synthesis. The most widely used method of preparation for 5 -substituted $1 H$-tetrazoles is [2+3] cycloaddition of azide anion to organic nitriles and many methods are reported in the literature.

Numbers of new catalysts have also been investigated till date and among those which serve the purpose are copper sulphate ${ }^{10}$, amine salt ${ }^{11}, \mathrm{Sb}_{2} \mathrm{O}_{3}{ }^{12}, \mathrm{~B}\left(\mathrm{C}_{6} \mathrm{H}_{5}\right)_{3}{ }^{13}, \mathrm{CdCl}_{2}{ }^{14}$ ceric ammonium nitrate ${ }^{15}, \mathrm{Et}_{3} \mathrm{n} \cdot \mathrm{HCl}^{16}, \mathrm{CuFe}_{2} \mathrm{O}_{3}{ }^{17}, \mathrm{FeCl}_{3} \cdot \mathrm{SiO}_{2}{ }^{18}$, ferric hydrogen sulphate ${ }^{19}$, reusable clay ${ }^{20}$, metal 
modified clay catalyst ${ }^{21}$, tungstate ${ }^{22}$, nano $\mathrm{TiO}_{2}{ }^{23}$, silica supported lanthanum tri phalate ${ }^{24}$, silver nano particle ${ }^{25}, \mathrm{ZnS}^{26}$, Nano $\mathrm{ZnS} / \mathrm{Co}_{3} \mathrm{O}_{4}{ }^{27}$, natural and reusable natrolite zeolite ${ }^{28}$ by using $\mathrm{NaN}_{3}$ Or $\mathrm{TMSN}_{3}$ The most convenient method to prepared 5 -substituted- $1 H$-tetrazoles is via $[2+3]$ cycloaddition reaction by using azide to and corresponding of nitriles. These all the catalysts drawback is one of that harsh reaction condition, long reactions times, use of toxic and corrosive reagents, difficulty to separation and recovery the catalyst, expensive and explosive along with volatile.

Thus, we developed new an advance technique in the context of synthetic methodology towards mentioned class of biologically important molecules using silica supported melamine trisulphonic acid (SMTSA) to prepared 5-substituted-1H-tetrazole. This method is convenient simple work, cheap and not toxic reaction, use of SMTSA as a mild Lewis acid catalyst, ease of separation and reusability of the catalyst in comparison to homogenous systems and good generality and efficiency towards a wide of range of substrates.

In an effort to develop an innovative and efficient heterogeneous catalytic system for [2+3] cycloaddition between benzonitrile and sodium azide to yield 5-phenyl- $1 \mathrm{H}$-tetrazole, we have examined various parameters such as efficiency of the catalyst and its reusability, effective catalyst loading, solvent and temperature effect.

\section{Results and Discussion}

In the present work on the application of silica supported MTSA in the organic reactions, we decided to carry out the reaction of benzonitrile and sodium azide catalyzed by silica supported MTSA as a recyclable catalyst.

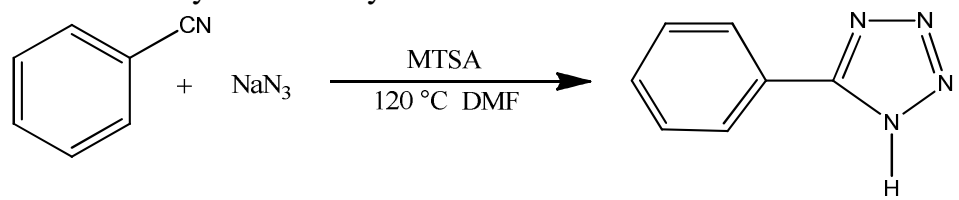

Scheme 1. Synthesis of 5-phenyl $1 H$-tetrazole by using MTSA

Table 1. Results of reactions of MTSA with different portions of benzonitrile and sodium azide

\begin{tabular}{cccccc}
\hline No. & Benzonitrile/ $\mathrm{NaN}_{3}$ & $\begin{array}{c}\text { Mol \% of } \\
\text { MTSA }\end{array}$ & $\begin{array}{c}\text { Temp./time, } \\
\mathrm{h}\end{array}$ & Solvent & Yield, \% \\
\hline 1 & $1: 1$ & 5 & $120 / 8$ & DMF & 2 \\
2 & $1: 2$ & 5 & $\mathrm{RT} / 4$ & few drop & 0.2 \\
3 & $1: 2$ & 5 & $120 / 8$ & DMF & 10 \\
4 & $1: 2$ & 10 & $120 / 5$ & $\mathrm{DMF}$ & 16 \\
5 & $1: 2$ & 15 & $120 / 5$ & $\mathrm{DMF}$ & 18 \\
7 & $1: 3$ & 5 & $120 / 24$ & DMF & 25 \\
8 & $1: 3$ & 5 & $\mathrm{RT}$ & without & Nil \\
9 & $1: 3$ & 5 & $\mathrm{RT} / 24$ & DMF & 3 \\
10 & $1: 3$ & 5 & $120 / 24$ & DMSO & 24 \\
11 & $1: 3$ & 10 & $120 / 6$ & DMSO & 28 \\
12 & $1: 3$ & 10 & $120 / 5$ & DMF & 31 \\
13 & $1: 3$ & 15 & $120 / 5$ & DMF & 36 \\
14 & $1: 3$ & 20 & $120 / 5$ & DMF & 43 \\
15 & $1: 3$ & 30 & $120 / 5$ & DMF & 24 \\
\hline
\end{tabular}


Initially, the reaction was carried out by using only melamine trisulphonic acid (MTSA) with different portions of benzonitrile, sodium azide and various solvent at decided temperature. The result is summarized in Table 1 . The reaction was monitored by TLC showed no significant outcome found of the reaction carried out. The synthesis of 5-phenyl$1 \mathrm{H}$ - tetrazole using MTSA using varied amount of benzonitrile/ $\mathrm{NaN}_{3}$ in the ratio of $1: 1$ to $1: 3$ and mol\% of MTSA ranging from 5\% to $30 \%$ were applied. When using up to 1:3 ratio of benzonitrile: $\mathrm{NaN}_{3}$ with polar solvent of DMF and 5 to 15 mol\% of MTSA, no significant yield was obtained. (Table 1, entries 1 to 8). Then we increased the proportion of MTSA applying similar condition the yield $43 \%$ was achieved where benzonitrile/ $\mathrm{NaN}_{3}$ used in $1: 3$ proportion using $20 \mathrm{~mol} \%$ of MTSA at $120{ }^{\circ} \mathrm{C}$ and DMF as a solvent (Table1, entry 14). Further it was observed that increase in the $\mathrm{mol} \%$ of the catalyst maintaining similar condition showed decrease in the yield.

Thus, by not getting considerable amount of yield in case of only using MTSA as a catalyst, we tried to modify this reaction in which we made silica supported melamine trisulphonic acid (SMTSA). This was used to carry out synthesis of 5-substituted-1 $\mathrm{H}$ tetrazole via [2+3] cycloaddition between various aromatic nitriles and sodium azide. The effect of solvent, reaction temperature and time on the reaction was systematically investigated and the results are summarized in Table 2. The optimized reaction conditions in presence of MTSA-SiO ${ }_{2}$ for the reaction were found to be under solvent-free condition for $12 \mathrm{~h}$ at the temperature of $120^{\circ} \mathrm{C}$. Thus, MTSA-SiO 2 was used as a catalyst in the present work. In order to elucidate the role of $\mathrm{MTSA}-\mathrm{SiO}_{2}$ as catalyst, a controlled reaction was conducted using benzonitrile and sodium azide by using DMF.

Table 2. The effect of solvent, reaction temperature and time on the reaction synthesis ${ }^{\mathrm{a}}$

\begin{tabular}{cccccc}
\hline Entry & Solvent & $\begin{array}{c}\text { Mol ratio of } \\
\text { SiO }_{2} \text {-MTSA, \% }\end{array}$ & $\begin{array}{c}\text { Mol ratio of } \\
\text { benzonitrile: } \text { NaN }_{3}\end{array}$ & Temp/time & Yield, \% \\
\hline 1 & Neat & 25 & $1: 2$ & $120 / 24$ & 1 \\
2 & DMSO & 25 & $1: 2$ & $120 / 10$ & 50 \\
$\mathbf{3}$ & DMF & 25 & $1: 2$ & $120 / 7$ & 57 \\
4 & Ethanol & 25 & $1: 2$ & $60 / 24$ & 45 \\
5 & 1,4-Dioxane & 50 & $1: 3$ & $100 / 24$ & 40 \\
6 & DCM & 50 & $1: 3$ & $80 / 24$ & 42 \\
7 & THF & 50 & $1: 3$ & $120 / 9$ & 60 \\
$\mathbf{8}$ & DMF & $\mathbf{5 0}$ & $\mathbf{1 : 3}$ & $\mathbf{1 2 0 / 6}$ & $\mathbf{8 5}$ \\
9 & Water & 50 & $1: 3$ & $100 / 48$ & Nil \\
10 & DMF & 50 & $1: 3$ & r.t/48 & Nil \\
11 & Ethanol & 50 & $1: 3$ & $60 / 24$ & 48 \\
12 & DMSO & 50 & $1: 3$ & $120 / 8$ & 75 \\
13 & Neat & 50 & $1: 3$ & $120 / 24$ & 3 \\
\hline
\end{tabular}

${ }^{a}$ Cycloaddition reaction of benzonitrile and sodium azide with different catalysts in DMF as a reaction medium. ${ }^{b}$ Isolated yields

In order to find the optimum reaction conditions for the [2+3] cycloaddition between sodium azide and various aromatic nitriles, preliminary efforts were mainly focused on the evaluation of different solvents. The model reaction was carried out between in the presence of MTSA-SiO ${ }_{2}$ catalyst under different solvents and at different temperatures and results are shown in Table 2. 
The results revealed that, DMF was found to be a superior one in terms of reaction time and the product yield among the solvents screened (Table 2, entry 8). An attempt was also made to catalyze the reaction in the absence of solvent but outcome was not promising (Table 2, entry 1). Polar solvents like ethanol produced $45 \%$ and $48 \%$ yields even after $24 \mathrm{~h}$ by using different mol proportion of benzonitrile, sodium azide and $\mathrm{MTSA}-\mathrm{SiO}_{2}$ (Table 2, entries 4 and 11). DMSO was also used as a solvent at various mol ratios but the yield was found to be lower than using DMF. (Table 2, entries 2 and 12). When using 1,4 dioxane produced only $40 \%$ (Table 2 , entry 5 ). This cycloaddition did not progress well while using chloro solvents such as chloroform or dichloromethane as medium (Table 2, entry 6). When, THF was employed as the reaction medium, the cycloaddition product was obtained in $60 \%$ yield in $9 \mathrm{~h}$ (Table 2, entry 7). Cycloaddition reaction also carried out at room temperature by using DMF as solvent and same amount of catalyst but there was no product obtained (Table 2, entry 10). The reaction was also tried in water, but the yield of the desired product was very low (Table 2, entry 9). As far the study carried out denoted that $50 \%$ mol ratio of catalyst with $1: 3$ benzonitrile: $\mathrm{NaN}_{3}$ used in [2+3] cycloaddition reaction was found to be essential.

Table 3. Effect of different weight of catalyst ${ }^{\mathrm{a}}$

\begin{tabular}{ccc}
\hline No. & Catalyst weight, $\mathrm{g}$ & ${\text { Yield, } \%^{\mathrm{b}}}^{\mathrm{a}}$ \\
\hline 1 & 0.02 & 8 \\
2 & 0.04 & 15 \\
3 & 0.06 & 20 \\
4 & 0.08 & 46 \\
5 & 0.1 & 54 \\
6 & 0.12 & 55 \\
7 & 0.14 & 58 \\
8 & 0.16 & 60 \\
9 & 0.18 & 77 \\
$\mathbf{1 0}$ & $\mathbf{0 . 2 0}$ & $\mathbf{8 5}$ \\
11 & 0.22 & 75 \\
12 & 0.24 & 66 \\
\hline
\end{tabular}

${ }^{a}$ Reaction of benzonitrile $(1 \mathrm{mmol})$ with sodium azide $(3 \mathrm{mmol})$ at $120{ }^{\circ} \mathrm{C}{ }^{b}$ Isolated yield

Amount of silica supported MTSA also played a vital role in this cycloaddition reaction. When benzonitrile was treated with sodium azide using 0.02 to $0.1 \mathrm{~g}$ SMTSA in DMF, the 5-phenyl- $1 H$-tetrazole was isolated by increasing yield (Table 3, entries 1-5). The catalyst amount was 0.12 , the product was obtained $55 \%$ (Table 3, entry 6 ). The yield was improved to $60 \%$ when the reaction was carried out in the presence of $0.16 \mathrm{~g}$ of SMTSA (Table 3, entry 8). In an attempt to improve the conversion and yield, the reaction was repeated using $0.20 \mathrm{~g}$ of SMTSA as a catalyst. Pleasantly, this resulted in complete conversion of benzonitrile into 5-phenyl- $1 H$-tetrazole within $6 \mathrm{~h}$ in excellent yield. Further improvement of yields was not observed on increasing the loading of the catalyst (Table 3, entry 10). Hence $0.20 \mathrm{~g}$ of catalyst was considered as an optimum catalyst concentration. Among the various solvents tested, DMF was found to be the best solvent giving maximum yields of the desired product. Whereas, while increasing the catalyst amount, the time required for the completion of the reaction was increased with lesser yield. The optimum amount of $\mathrm{SiO}_{2}$ MTSA was found to be $0.2 \mathrm{~g}$ in the presence of nitrile $(1 \mathrm{mmol})$ and sodium azide $(3 \mathrm{mmol})$ in DMF (6 mL) for the cycloaddition reaction under study. 
We investigated the substrate scope and generality of the protocol by employing structurally divergent benzonitriles bearing activating and deactivating groups and few aromatic and heteroaromatic including aliphatic nitriles. The methodology worked well for most of the nitriles which gave excellent yields over and around $80 \%$ and all the reactions proceeded to completion within 6 hours.

Table 4. Silica supported MTSA catalyzed synthesis of 5-substituted tetrazoles

(1)

${ }^{a}$ The reaction between various nitriles ( 1 equiv.) and sodium azide ( 3 equiv.) was performed in the presence of $\mathrm{SiO}_{2}-\mathrm{MTSA}(0.2 \mathrm{~g})$ in $\mathrm{DMF}(6 \mathrm{~mL})$ at $120^{\circ} \mathrm{C}$. ${ }^{b}$ Isolated yield

As shown in scheme 2 different benzonitriles reacted with sodium azide without any significant difference in the reaction time to give the corresponding 5-substituted tetrazole and their derivatives in good yield. The method has the ability to tolerate other functional groups such as methoxy, methyl and halides. Among the various nitriles tested, the aromatic 
nitriles with electron withdrawing substituent gave excellent yields in a very short time to conversion of nitrile compounds relatively and the desire product was obtained in excellent yield (Table 4, entries 3-7). Moreover, electron donating groups at ortho or meta position of aromatic ring gave the corresponding tetrazoles in high yields, although longer reaction times were required (Table 4, entries 2, 10 and 12). Likewise, aliphatic nitriles react similarly and provide good yields of the corresponding tetrazoles (Table 4, entries 8 and 9). While it was particularly noticed that hydroxy substitution at ortho position had given comparatively lower yield and longer reaction time may be due to steric effect (Table 4, entry 12). Other aryl nitriles such as phenyl acetonitrile also reacted easily to furnish the corresponding tetrazoles in $80 \%$, respectively (Table 4, entry 11). Heterocyclic nitriles i.e. nicotinonitrile was also used as a substrate and found to be extremely reactive, affording the relative tetrazole in $79 \%$ yield after $7 \mathrm{~h}$. The activity of nitrile compound towards azide ion plays an important role in this cycloaddition reaction. In comparison the cycloaddition reaction of aromatic nitriles with electron withdrawing substituent such as $-\mathrm{Cl},-\mathrm{Br},-\mathrm{CN}$ and $-\mathrm{NO}_{2}$ is faster than the reaction of aromatic nitrile compound with electron donating substituent such as $-\mathrm{NH}_{2},-\mathrm{OCH}_{3},-\mathrm{CH}_{3}$, $\mathrm{OCH}_{2} \mathrm{CH}_{3}$ and $-\mathrm{OH}$. From Table 4, it is evident that, excellent to good results were obtained with alkyl, aryl, despite the different activities of the nitrile derivatives.

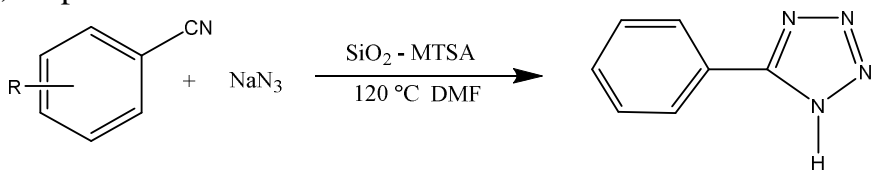

Scheme 2. Synthesis of 5-phenyl-1H-tetrazole (1) in the presence of $\mathrm{SiO}_{2} \cdot \mathrm{MTSA}$

The prime importance of heterogeneous catalyst over the homogeneous counterpart is its simplicity of separation and reusability without loss of activity. The reusability of catalyst is important for the large-scale operation and industrial point of view. Therefore, the recovery and reusability of $\mathrm{SiO}_{2}$-MTSA was examined (Figure 1). In consequence with this, we successfully achieved the recovery of catalyst from reaction mixture by simple filtration and the solid residue obtained was subjected to centrifugal washing with ethanol $(2 \times 15 \mathrm{~mL})$ by drying in an oven at $100{ }^{\circ} \mathrm{C}$ for 3-4 hours. This assisted in keeping the catalyst surface active. It is noteworthy, that the recycled catalyst retained optimum activity until $4^{\text {th }}$ cycle after which a drop-in yield was observed.

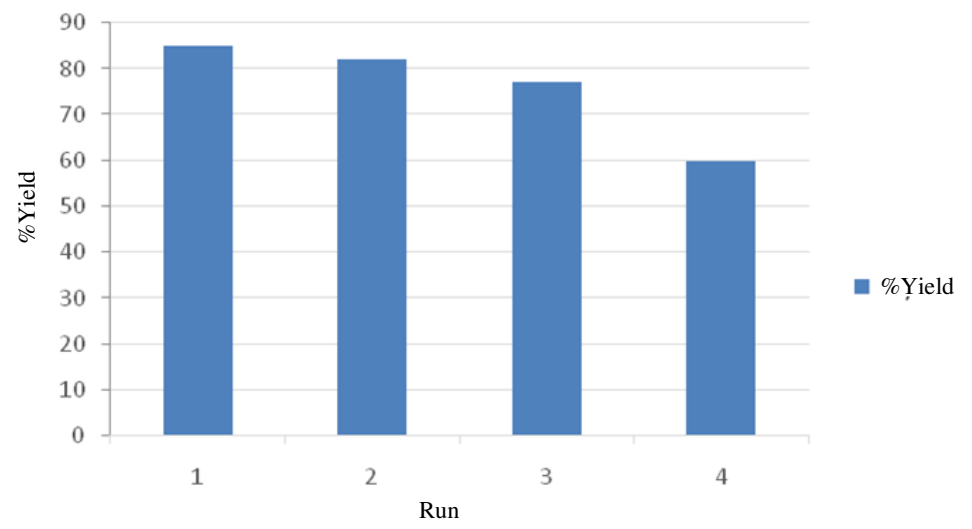

Figure 1. Reusability of $\mathrm{SiO}_{2}-\mathrm{MTSA}$

(Conditions:Benzonitriles (1 equiv.) and sodium azide (3 equiv.) was performed in the presence of $\mathrm{SiO}_{2}-\mathrm{MTSA}(0.2 \mathrm{~g})$ in $\mathrm{DMF}(6 \mathrm{~mL})$ at $120{ }^{\circ} \mathrm{C}$ 


\section{Reusability of $\mathrm{SiO}_{2}$-MTSA}

\section{General procedure of 5-substituted-1H-tetrazole}

Briefly, SMTSA $(0.2 \mathrm{~g})$ was added to the reaction mixture of the solution of benzonitrile $(1 \mathrm{mmol})$ in DMF $(6 \mathrm{~mL})$ and sodium azide $(3 \mathrm{mmol})$ with stirring for $6 \mathrm{~h}$ at $120{ }^{\circ} \mathrm{C}$. The reaction was monitored by TLC ( $n$-hexane:ethanol-9:1) and after completion of the reaction, the catalyst was removed by filtration and the filtrate was treated with ethyl acetate $(20 \mathrm{~mL})$ and $4 \mathrm{~N} \mathrm{HCl}(20 \mathrm{~mL})$ and stirred vigorously. The resultant organic layer was separated and the aqueous layer was extracted with ethyl acetate $(10 \mathrm{~mL})$. The combined organic layer was washed with water $(8 \mathrm{~mL})$ and concentrated it to give yield the crude white crystalline solid 5-phenyl tetrazole in $80-82 \%$ yield. The crude tetrazole was then recrystallized by mixture of solvents (50\% ethyl acetate in hexane) and subsequently characterized by ${ }^{1} \mathrm{H}$ NMR, ${ }^{13} \mathrm{C}$ NMR, IR.

\section{Preparation of silica supported melamine trisulphonic acid (SMTSA catalyst) ${ }^{29}$}

A $250 \mathrm{~mL}$ suction flask charged with chlorosulfonic acid $(10.5 \mathrm{~g}$, ca. $6 \mathrm{~mL}, 90 \mathrm{mmol})$ in $\mathrm{CH}_{2} \mathrm{Cl}_{2}(10 \mathrm{~mL})$ was equipped with a gas inlet tube for conducting $\mathrm{HCl}$ gas over an adsorbing solution i.e. water. Melamine (3.78 g, $30 \mathrm{mmol})$ was added in small portions over a period of $30 \mathrm{~min}$. at room temperature under $\mathrm{N}_{2}(\mathrm{~g})$. $\mathrm{HCl}$ gas evolved from the reaction vessel immediately. After completion of the addition of melamine, the mixture was shaken for $30 \mathrm{~min}$; meanwhile, the residual $\mathrm{HCl}$ was eliminated by suction. Then the mixture was washed with excess $\mathrm{CH}_{2} \mathrm{Cl}_{2}$ to remove the unreacted chloro sulphonic acid. Finally, a white solid powder was obtained $(\sim 10 \mathrm{~g}, 91 \%)$. Then $18.2 \mathrm{~g}$ silica gel was added to this white solid and stirred those for $30 \mathrm{~min}$. Finally, dried and grayish solid material was obtained $(28.1 \mathrm{~g})$. General scheme for synthesis of silica melamine trisulfonic acid is given in Scheme 3.<smiles>Nc1nc(N)nc(N)n1</smiles>

Scheme 3. Synthesis of silica melamine tri sulphonic acid

Physical, spectral and analytical data of compounds (Entry 1-13, Table 4) 5-Phenyl-1H tetrazole ${ }^{30}(\mathbf{2 a})$

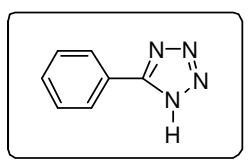

M.P. $210-215{ }^{\circ} \mathrm{C}$ (Lit. $214-216{ }^{\circ} \mathrm{C}$ ); IR (KBr) vmax $/ \mathrm{cm}^{-1}: 3130,3039$, 2978, 2770, 2599, 2493, 1617, 1569, 1461, 1402, 1168, 1056, $730 ;{ }^{1} \mathrm{H}$ NMR (400 MHz, DMSO-d 6 ) d $7.61,8.05 ;{ }^{13} \mathrm{C}$ NMR (100 MHz, DMSO- $\left.\mathrm{d}_{6}\right)$ d 125.6, 126.4, 128.9, 130.7, 157.7; CHN $\left(\mathrm{C}_{7} \mathrm{H}_{6} \mathrm{~N}_{4}\right)$ calc. (\%): C (57.5), H (4.1), N (38.3); found (\%): C (56.4), H (4.1), N (37.6).

\section{5-(3-Methoxyphenyl)-1H-tetrazole ${ }^{31}$ (2b)}

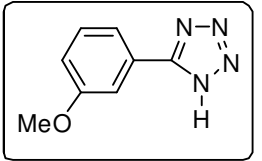

White solid, M.P. $155-160{ }^{\circ} \mathrm{C}$ (Lit. $\left.156-158^{\circ} \mathrm{C}\right)$. IR(KBr) $v \max / \mathrm{cm}^{-1}$ : 1490, 1564, 1711, $2843{ }^{1} \mathrm{H}$ NMR $\left(500 \mathrm{~Hz}\right.$, DMSO-d $\left.{ }_{6}\right): 16.88$ (brs, $1 \mathrm{H}$, N-H), 7.64-7.62 (m, $1 \mathrm{H}, \mathrm{Ar}-\mathrm{H}), 7.60-7.59$ (m, $1 \mathrm{H}, \mathrm{Ar}-\mathrm{H}), 7.53$ (t, $1 \mathrm{H}, \mathrm{J}$ $=8.05 \mathrm{~Hz}, \mathrm{Ar}-\mathrm{H}), 7.17$ (ddd, $1 \mathrm{H}, \mathrm{J}=0.8,2.55,3.4 \mathrm{~Hz}, \mathrm{Ar}-\mathrm{H}), 3.86$ (s, 3 $\left.\mathrm{H}, \mathrm{CH}_{3}-\mathrm{H}\right) \mathrm{ppm} ; \mathrm{CHN}\left(\mathrm{C}_{8} \mathrm{H}_{8} \mathrm{ON}_{4}\right)$ calc $(\%):{ }^{13} \mathrm{C}$ NMR (125 Hz,DMSO$\left.\mathrm{d}_{6}\right): 159.7,155.0,130.6,125.2,119.1,117.0,112.0,55.3 \mathrm{ppm}$. 


\section{5-(4-Bromophenyl)-1H-tetrazole ${ }^{18}(2 \mathrm{c})$}

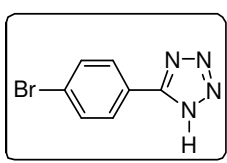

M.P. $277-279{ }^{\circ} \mathrm{C}$ (Lit. $\left.275-280{ }^{\circ} \mathrm{C}\right)$; IR (KBr) $v \max / \mathrm{cm}^{-1}$ : 3090, 2903, 2849, 2730, 2630, 1654, 1484,1159, 1070, 1012, 745, 509; ${ }^{1} \mathrm{H}$ NMR (400 MHz, DMSO-d $\left.{ }^{6}\right)$ d 7.80 (d, 2H, Ph), 7.95 (d, 2H, Ph);

\section{5-(4-Nitrophenyl)-1H-tetrazole ${ }^{18}(2 d)$}

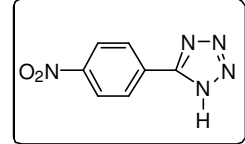

M.P. $215-220{ }^{\circ} \mathrm{C}$ (Lit. $219-220{ }^{\circ} \mathrm{C}$ ); IR (KBr) vmax $/ \mathrm{cm}^{-1}: 3450,3100$, 3095, 2978, 2903, 2819, 2676, 1568, 1100, 999, 730; ${ }^{1} \mathrm{H}$ NMR (400 MHz, DMSO-d $\left.{ }_{6}\right)$ d 8.33(d, 2H, Ph), 8.49 (d, 2H, Ph)

\section{5-(4-Chlorophenyl)-1H-tetrazole ${ }^{18}(2 \boldsymbol{e})$}

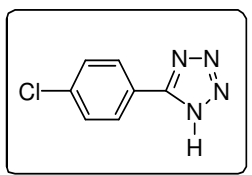

M.P. $261-262{ }^{\circ} \mathrm{C}$ (Lit. $\left.261-263{ }^{\circ} \mathrm{C}\right)$; IR (KBr) vmax $/ \mathrm{cm}^{-1}$ : 3092, 3060, 3007, 2978, 2907, 2851, 2725, 2622, 1609, 1564, 1486, 1160, 1096, 1053, 1020, 990, 833, 745, 508; ${ }^{1} \mathrm{H}$ NMR (400 MHz, DMSO-d 6 ) d 7.68 (d, 2H, J $8.4 \mathrm{~Hz}, \mathrm{Ph}), 8.05$ (d, 2H, J $8.8 \mathrm{~Hz}, \mathrm{Ph})$.

5-(3-Bromophenyl)-1H-tetrazole ${ }^{18}(2 f)$

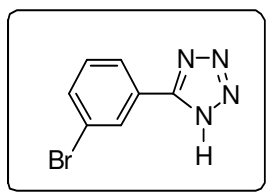

M.P. $153-154{ }^{\circ} \mathrm{C}$ (Lit. $150-153{ }^{\circ} \mathrm{C}$ ); IR (KBr) vmax $/ \mathrm{cm}^{-1}$ : 3450,3090, 2903, 2849, 2730, 2630, 1654, 1484, 1012, 745, 509; ${ }^{1} \mathrm{H}$ NMR (400 MHz, DMSO-d6) d 7.50 (d, 1H, Ph), 7.75 (d, 1H, Ph),8.02(dt, $\mathrm{J}=8.1 \mathrm{~Hz}, 1 \mathrm{H})$

5-(2-Naphthyl)-1H tetrazole ${ }^{18}(\mathbf{2 g})$

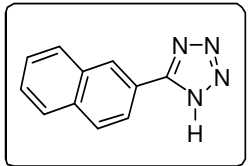

M.P. $200-205{ }^{\circ} \mathrm{C}$ (Lit 205-207) ; IR (KBr) vmax $/ \mathrm{cm}^{-1}$ : 3421, 3053, 2812, 2721, 1626, 1599, 1518, 1491, 1383, 1352, 1257, 1121, 1102, 966, 864; ${ }^{1} \mathrm{H}$ NMR (400 MHz, DMSO-d $\left.{ }_{6}\right) \delta(\mathrm{ppm}): 8.67(\mathrm{~m}, 1 \mathrm{H}), 8.12$ $(\mathrm{m}, 2 \mathrm{H}), 8.06(\mathrm{~m}, 1 \mathrm{H}), 7.99(\mathrm{~m}, 1 \mathrm{H}), 7.61(\mathrm{~m}, 2 \mathrm{H})$.

\section{5-(1-Pentyl)-1H tetrazole ${ }^{31}$ (2h)}

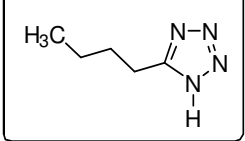

M.P. $90-95{ }^{\circ} \mathrm{C}$ (Lit 92-94); IR (KBr) $v \max / \mathrm{cm}^{-1}$ : 3414, 2854, 2204,1602, 1498, 1386, 1348, 837, 771; ${ }^{1} \mathrm{H}$ NMR (400 MHz, DMSO$\left.\mathrm{d}_{6}\right) \delta(\mathrm{ppm}): 3.71(\mathrm{~s}, 2 \mathrm{H}), 7.84(\mathrm{br} \mathrm{s}, 1 \mathrm{H}) \mathrm{d} .1 .00(\mathrm{~d}, 6 \mathrm{H}, \mathrm{J} 5 \mathrm{~Hz}, 2$ $\left.\mathrm{CH}_{3}\right), 3.10$ (t, $2 \mathrm{H}, \mathrm{J} 6 \mathrm{~Hz},-\mathrm{CH}_{2}-$ ).

\section{5-Isobutyl-1H-tetrazole ${ }^{31}(2 \mathrm{i})$}

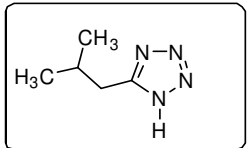

M.P. $50-55{ }^{\circ} \mathrm{C}$ (Lit. 53.5-54 ${ }^{\circ} \mathrm{C}$ ); IR (KBr) $v \max / \mathrm{cm}^{-1}$ : 3089, 3063, 2971, 2901, 2845, 2765, 2729, 2633, 1605, 1482, 1454, 1430, 1156, $1075,1053,1017,990,829,772,743,502$

\section{5-(3-Methylphenyl)-1H-tetrazole ${ }^{31}(2 j)$}

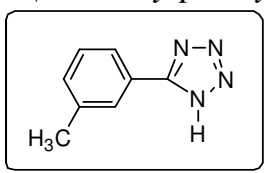

M.P. $145-150{ }^{\circ} \mathrm{C}$ (Lit. $151-152^{\circ} \mathrm{C}$ ); IR (KBr) vmax $/ \mathrm{cm}^{-1}: 3120,3061$, 2979, 2917, 2871, 2746, 2611, 2490,1728, 1605, 1565, 1486, 1463, 1150, 1060, 1038, 802, 741, 705, 687; ${ }^{1} \mathrm{H}$ NMR (400 MHz, DMSO-d 6 ) $\delta(\mathrm{ppm}): 2.43\left(\mathrm{~s}, 3 \mathrm{H}, \mathrm{CH}_{3}\right), 7.40-7.90(\mathrm{~m}, 4 \mathrm{H}, \mathrm{Ph})$. 


\section{5-Benzyl-1H-tetrazole ${ }^{31}(\mathbf{2 k})$}

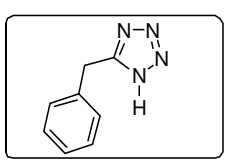

M.P. $115-120{ }^{\circ} \mathrm{C}$ (Lit. $118-120{ }^{\circ} \mathrm{C}$ ); IR (KBr) vmax $/ \mathrm{cm}^{-1}$ : 3109, 3031, 2984, 2945, 2863, 2778, 2704,2594, 1768, 1707, 1638, 1549, 1533, 1494, $1457,1241,1108,1074,772,734,695 ;{ }^{1} \mathrm{H}$ NMR (400 MHz, DMSO-d 6 ) $\delta$ (ppm):4.30 (s, 2H, $\left.-\mathrm{CH}_{2}-\right), 7.31(\mathrm{~s}, 5 \mathrm{H}, \mathrm{Ph})$.

5-(3-Hydroxyphenyl)-1H-tetrazole $e^{15}$ (2l)

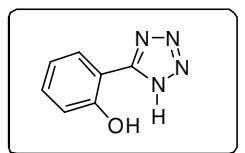

M.P. $179-182{ }^{\circ} \mathrm{C}$ ( Lit. $178-180{ }^{\circ} \mathrm{C}$ ); IR (KBr) vmax $/ \mathrm{cm}^{-1}$ : 3252, 3101, 3066, 3019, 3000-2200, 1615, 1599, 1511, 1466, 1413, 1282, 832, 752, 514; ${ }^{1} \mathrm{H}$ NMR (400 MHz, DMSO-d $\left.{ }_{6}\right) \delta$ (ppm):6.97 (d, 2H, J $8.4 \mathrm{~Hz}$, $\mathrm{Ph}), 7.87$ (d, 2H, J $8.8 \mathrm{~Hz}, \mathrm{Ph}), 10.20$ (br s, OH).

4-(1H-Tetrazol-5-yl)pyridine ${ }^{31}(2 \mathrm{~m})$

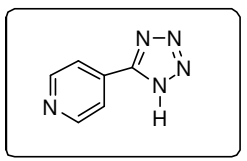

M.P. $254-255{ }^{\circ} \mathrm{C}$ (Lit. $\left.255-258{ }^{\circ} \mathrm{C}\right)$; IR (KBr) vmax $/ \mathrm{cm}^{-1}: 3485,3264$, $3099,3035,2966,1624,1529,1435,1388,1123,1096,1042,1022,845$, $730,674,593,465$.

\section{Conclusion}

SMTSA was successfully prepared and developed a mild, convenient and efficient protocol for the synthesis 5-substituted- $1 H$-tetrazoles from nitriles and amines using silica supported melamine trisulphonic acid catalyst (SMTSA) efficient and recyclable catalyst. This method gives notable advantages such as easy separation of the catalyst excellent yields, short reaction times, non-toxic metal catalyst and simplicity of operation make this method a facile tool for the synthesis of tetrazoles.

\section{Acknowledgement}

I thankful to government Science College, a part of veer narmad south Gujarat University, to give me an opportunity for a research place. I also thankful to Dhanvatry Pharmacy College, Kim to provide data of analysis of my compound. I thankful to Punjab University, Chandigarh, India who are gratefully acknowledged.

\section{References}

1. Butler R N, In Comprehensive Heterocyclic Chemistry II; Katritzky A R, Rees C W and Scriven E F V, Eds.; Pergamon: New York, 1996, 4, 621.

2. Herr R J, Bioorg Med Chem., 2002, 10(11), 3379-3393; DOI:10.1016/S09680896(02)00239-0

3. (a) Holland G F and Pereira J N, J Med Chem., 1067, 10(2), 149-154; DOI:10.1021/jm00314a004 (b) Figdor S K and Schach von Wittenau M, J Med Chem., 1967, 10, 1158; (c) Esplin D W and Woodbury D M, J Pharmacol Exp Ther., 1956, 118(2), 129-138.

4. Flippin L A, Tetrahedron Lett., 1991, 32(47), 6857-6860; DOI:10.1016/00404039(91)80425-6

5. Rhonnstad P and Wensbo D, Tetrahedron Lett., 2002, 43(17), 3137; DOI:10.1016/S0040-4039(02)00490-2

6. Ek F, Wistrand L G and Frejd T, Tetrahedron, 2003, 59(35), 6759-6769; DOI:10.1016/S0040-4020(03)00818-4

7. Sandmann G, Schneider C, Boger P Z and Naturforsch C, Biosci., 1996, 51, 534-539. 
8. Jursic B S and Leblanc B W, J Heterocycl Chem., 1998, 35(2), 405-408; DOI:10.1002/jhet.5570350224

9. Zhao-Xu C and Heming X, Int J Quantum Chem., 2000, 79(6), 350-357; DOI:10.1002/1097-461X(2000)79:6<350::AID-QUA3>3.0.CO;2-T

10. Jin T, Kitahara F, Kamijo S and Yamamoto Y, Tetrahedron Lett., 2008, 49(17), 28242827; DOI:10.1016/j.tetlet.2008.02.115

11. Yi Zhoua, Cheng Yao, Renjie Ni and Gaowen Yang, Synth Commun., 2010, 40, 2624-2632

12. Venkateshwarlu G, Rajanna K C and Saiprakash P K, Synth Commun., 2009, 39(3), 426-432; DOI:10.1080/00397910802378381

13. Kumar Prajapti S, Nagarsenkar A and Babu B N, Tetrahedron Lett., 2014, 55(24), 3507-3510; DOI:10.1016/j.tetlet.2014.04.089

14. Venkateshwarlu G, Premalatha A, Rajanna K C and Saiprakash P K, Synth Commun., 2009, 39(24), 4479-4485; DOI:10.1080/00397910902917682

15. Sivaguru P, Bhuvaneswari K, Ramkumar R and Lalitha A, Tetrahedron Lett., 2014, 55(41), 5683-5686; DOI:10.1016/j.tetlet.2014.08.066

16. Roh J, Atramonova T V, Vavrova K, Koldobskii G I and Hrabalek A, Synthesis, 2009, 13, 2175-2178; DOI:10.1055/s-0029-1216840

17. Sreedhar B, Suresh Kumar A, Divya Yada, Tetrahedron Lett., 2011, 52(28), 35653569; DOI:10.1016/j.tetlet.2011.04.094

18. Nasrollahzadeh M, Bayat Yb, Davood Habibi, S. Moshaee, Tetrahedron Lett., 2009, 50(31), 4435-4438; DOI:10.1016/j.tetlet.2009.05.048

19. Eshghi H, Seyedi S and Rahimi Zarei E, ISRN Org Chem, 2011, 1-5; DOI: $10.5402 / 2011 / 195850$

20. Rama V, Kanagaraj K and Pitchumani K, J Org Chem., 2011, 76(21), 9090-9095; DOI:10.1021/jo201261w

21. Chermahini A N, Teimouri A and Ali Moaddeli, Heteroatom Chem., 2011, 22(2), 168-173; DOI:10.1002/hc.20672

22. He J, Li B, Chen F, Xu Z and Gui Yin, J Mole Cat A: Chem 2009, 304(1-2), 135-138; DOI:10.1016/j.molcata.2009.01.037

23. Sajadi S M, Naderi M and Babadoust S, J Nat Sci Res., 2011, 1, 10-17.

24. Meshrama G A, Deshpandea S S, Wagha P A and Vala V A, Tetrahedron Lett, 2015, 55(25), 3557-3560; DOI:10.1016/j.tetlet.2014.04.101

25. Mani P, Sharma C, Kumar S and Awasthi S, J Mole Cat A: Chem., 2014, 392, 150156; DOI:10.1016/j.molcata.2014.05.008

26. Lang L, Hong Zhou, Xue M, Wang X and Xu Z, Mater Lett., 2013, 106, 443-446; DOI:10.1016/j.matlet.2013.05.067

27. Mohammad Sajadia S and Maham M, Lett Org Chem., 2014, 11(1), 35-39; DOI:10.2174/157017861101140113160634

28. Gauglitz G and Vo-Dinh T, Handbook of Spectroscopy, Wiley-VCH Verlag Gmbh and Co. Kga, Weinheim, (2003) ISBN 3-527-29782-0.

29. (a) Savaliya M L and Dholakiya B Z, Appl Cat A: Gen., 2015, 494, 12-21; DOI:10.1016/j.apcata.2015.01.015 (b) Shirinia F, Zolfigolb M A and Albadia J, $J$ Iran Chem Soc., 2010, 7(4), 895-899; DOI:10.1007\%2FBF03246085 (c) Mehrjardi M F and Ghanemi K, Jordan J Chem., 2012, 7, 393-399; (d) Sheik Mansoor S, Aswin K, Logaiya K and Sudhan S P N, J King Saud Univ - Sci., 2013, 25(3), 191-199; DOI:10.1016/j.jksus.2013.02.001 (e) Zare A and Monfared F, Iran Chem Commun., 2014, 2, 1-17 
30. Madhusudana Reddy M B and Pasha M A, Synth Commu., 2011, 41(14), 2081-2085; DOI:10.1080/00397911.2010.497593

31. Batool A and Soodabeh R, J Braz Chem Soc., 2012, 23(12), 2197-2203; DOI:10.1590/S0103-50532013005000005 